\title{
The Ross procedure in children: a systematic review
}

\author{
Morgan K. Moroi, Emile A. Bacha, David M. Kalfa \\ Section of Congenital and Pediatric Cardiothoracic Surgery, Division of Cardiac, Thoracic and Vascular Surgery, Department of Surgery, Morgan \\ Stanley Children's Hospital, New York-Presbyterian Hospital/Columbia University Medical Center, New York, NY, USA \\ Correspondence to: David M. Kalfa, MD, PhD. Columbia University College of Physicians and Surgeons, 3959 Broadway, New York, NY 10032, USA. \\ Email: dk2757@cumc.columbia.edu.
}

Background: The Ross procedure involves autograft transplantation of the native pulmonary valve into the aortic position and reconstruction of the right ventricular outflow tract (RVOT) with a homograft. The operation offers the advantages of a native valve with excellent hemodynamic performance, the avoidance of anticoagulation, and growth potential. Conversely, the operation is technically demanding and imposes the risk of turning single-valve disease into double-valve disease. This systematic review reports outcomes of pediatric patients undergoing the Ross procedure.

Methods: An electronic search identified studies reporting outcomes on pediatric patients (mean age $<18$ years, max age <21 years) undergoing the Ross procedure. Long-term outcomes, including early mortality, late mortality, sudden unexpected unexplained death, reoperation due to failure of the pulmonary autograft or RVOT reconstruction, thromboembolic events, bleeding events, and endocarditis-related complications, were evaluated.

Results: Upon review of 2,035 publications, 30 studies and 3,156 pediatric patients were included. Patients had a median age of 9.5 years and median follow-up period of 5.7 years. Early mortality rates varied from 0.0 to $17.0 \%$ and were increased in the neonatal population. Late mortality rates were much lower (0.04-1.83 \%/year). Reoperation due to pulmonary autograft failure occurred at rates of $0.37-2.81 \% /$ year and reoperation due to RVOT reconstruction failure was required at rates of $0.34-4.76 \%$ /year. Thromboembolic, bleeding, and endocarditis events were reported to occur at rates of $0.00-0.58,0.00-0.39$, and 0.00-1.68\%/year, respectively.

Conclusions: The Ross operation offers a durable aortic valve replacement (AVR) option in the pediatric population that offers favorable survival, excellent hemodynamics, growth potential, decreased risk of complications, and avoidance of anticoagulation. Larger multi-institutional registries focusing on pediatric patients are necessary to provide more robust evidence to further support use of the Ross procedure in this population.

Keywords: Ross; aortic valve replacement (AVR); pulmonary autograft

Submitted Nov 05, 2020. Accepted for publication Jun 10, 2021.

doi: 10.21037/acs-2020-rp-23

View this article at: https://dx.doi.org/10.21037/acs-2020-rp-23

\section{Introduction}

Aortic valve pathology is one of the most common congenital heart pathologies, occurring in $5 \%$ of all children with heart disease $(1,2)$. It includes congenital aortic valve anomalies as well as acquired aortic valve diseases, with congenital anomalies being caused by abnormal leaflet and/or annular morphologies and acquired aortic valve diseases including rheumatic heart disease and endocarditis. Aortic valve disease can ultimately lead to stenosis, insufficiency, or both, causing changes in both cardiac function and hemodynamics. Regardless of pathology, many of these patients will require intervention. While pediatric patients with congenital aortic valve disease may initially be palliated with transcatheter or aortic valve repair strategies, most will eventually require aortic valve replacement (AVR). 
Valve selection in children tends to be challenging due to associated congenital heart defects, size limitations, somatic growth, and the fact that prosthetic valves are not as durable as they are in adult patients. Traditionally, choices for AVR include: mechanical valves, bioprosthetic valves, and biological valves (i.e., aortic valve homografts). Each option is associated with its own uses and limitations, and no option is the perfect substitute. Mechanical valves are easy to implant and the most durable prosthetic valve in young patients. However, they require lifelong anticoagulation, posing an increased risk for hemorrhagic and thromboembolic complications. Bioprosthetic valves, while used in the older adult population, are not frequently used in younger patients due to poor durability, with $49 \%$ of patients less than 35 years old experiencing valve degeneration at 10 years postoperatively (3). The effect of patient age on valve durability is also observed with aortic valve homografts. In addition, limited availability and increased complexity of reoperation have further restricted the use of homografts in the pediatric population. Of note, all of these options are associated with the eventual development of patientprosthesis mismatch. Depending on the age at implantation, most children outgrow their implanted valve and develop the need for subsequent reoperation to upsize their prosthesis.

In 1967, Donald Ross described a new AVR strategy, using the patient's own pulmonary valve to replace the diseased aortic valve and then reconstructing the right ventricular outflow tract (RVOT) using a homograft (4). While technically challenging, this option offers an attractive solution for the management of aortic valve disease in children and young adults. The pulmonary autograft grows in accordance to somatic growth of the patient, displays improved longevity relative to bioprostheses and homografts, avoids the burden of anticoagulation, and allows for a hemodynamic profile that is similar to the native aortic valve (5-7). It also provides a long-term survival that matches the general population of children and young adults (8).

That is not to say that the Ross procedure is without risk. The operation is technically demanding, and late autograft failure and aortic root dilatation have been reported to occur (6,7,9-11). In addition, unlike with other AVR options, it is argued that the Ross procedure has the potential to turn single-valve disease into double-valve disease, with future reinterventions not only being possible for the neoaortic valve but also the reconstructed RVOT (12).

Despite this, the Ross procedure remains a feasible option for pediatric patients with aortic valve disease requiring replacement. Herein, we perform a systematic review focusing on the outcomes of pediatric patients undergoing the Ross procedure.

\section{Methods}

\section{Literature search strategy}

Electronic searches were performed using PubMed and Embase from their date of inception to September 1, 2020. To achieve maximum sensitivity of the search strategy, the following query was performed: [(Ross) AND (aortic valve) AND ((pediatric) OR (congenital) OR (neonate) OR (infant) OR (child) OR (adolescent))]. All identified articles were systematically assessed using the inclusion and exclusion criteria. Additional references for discussion were obtained by reference list searches or targeted database searches.

\section{Selection criteria}

Eligible studies for the present systematic review included those which examined the use of the Ross procedure in pediatric patients. Primary endpoints were early mortality and late mortality. Early mortality was defined as death within 30 days of Ross procedure, and late mortality was defined as death after 30 days postoperatively. Secondary endpoints included sudden unexpected and unexplained death, pulmonary autograft reoperation, RVOT reoperation, thromboembolism or valve thrombosis, bleeding, and endocarditis. A limit was placed on mean patient age $(<18$ years) and maximum patient age $(<21$ years) at the time of surgery to exclude adult patient data. Studies were screened to include more than 30 patients.

All publications were limited to those involving human subjects and those written in the English language. Duplications were removed and only the most recent or most complete study was included in cases where study populations overlapped. Abstracts, case reports, conference presentations, editorials, and expert opinions were omitted. Review articles were excluded due to potential duplication of results.

\section{Data extraction and critical appraisal}

All data were extracted from the texts, tables, and figures of main articles. One reviewer (MK Moroi) independently reviewed each article for inclusion or exclusion. Year of publication, location of study, study period, number of patients, study design, and follow-up (patient-years and mean/median follow-up) were recorded as study characteristics. Mean age at time of surgery, cause of aortic pathology (i.e., congenital, 


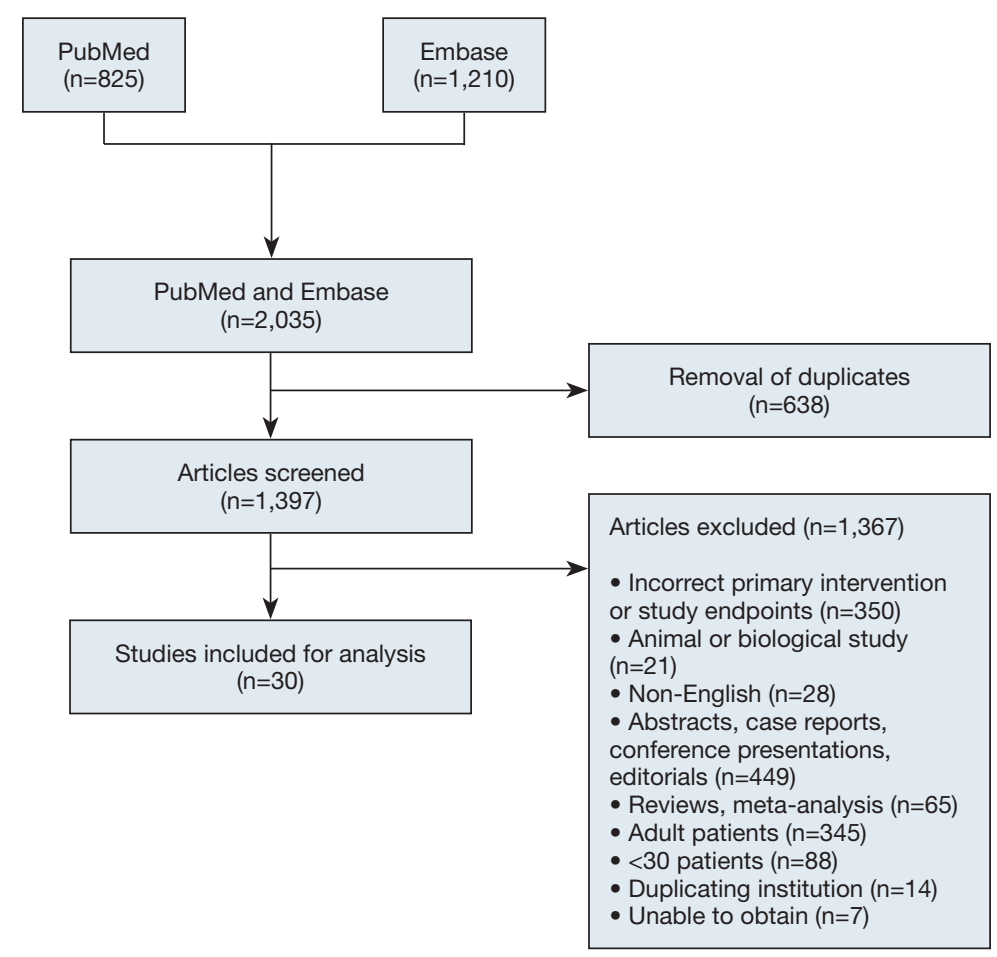

Figure 1 Flow chart of literature search.

rheumatic heart disease, endocarditis), preoperative indication for Ross procedure (i.e., aortic stenosis, aortic regurgitation, both), previous cardiac interventions, concomitant procedures, and annular enlargement procedures were reported as baseline patient characteristics. Primary and secondary endpoints were also collected for each study.

\section{Statistical analysis}

Data were summarized using Microsoft Office Excel 2016 (Microsoft Corp, Redmond, WA, USA). Categorical and continuous variables were recorded as displayed in the text. Late mortality and secondary endpoints (i.e., sudden unexpected and unexplained death, pulmonary autograft reoperation, RVOT reoperation, thromboembolism or valve thrombosis, bleeding, and endocarditis) were displayed in terms of event per patient-year.

\section{Results}

\section{Literature search}

In total, an exhaustive search of the medical literature identified 2,035 articles (Figure 1). After removal of duplicates and applying the inclusion and exclusion criteria, a total of 30 publications were included in the systematic review, encompassing 3,156 pediatric patients undergoing the Ross procedure. Twelve studies were included from 1991 to 2010 (13-24). Eighteen studies were included from 2011 to 2020 (25-42).

\section{Study characteristics and baseline patient characteristics}

An overview of the publications included is outlined in Table 1. The median size of included study was 69.5 patients (interquartile range, $47-144$ patients) with a median age of 9.5 years (interquartile range, 7.4-11.3 years). Median followup period was 5.7 years (interquartile range, $5.0-8.8$ years). The primary indication for Ross procedure was congenital aortic valve disease not amenable to transcatheter intervention or surgical repair. Endocarditis and rheumatic heart disease were also indications for undergoing the Ross procedure, although rates of occurrence were much lower. In terms of congenital aortic pathology, patients most frequently had a combination of aortic stenosis and insufficiency preoperatively (median $47 \%$ ), followed by isolated aortic stenosis (median 28\%) and isolated aortic insufficiency (median 19\%). Studies described absolute contraindications to the Ross procedure 
๖े

递兽

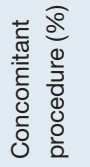
芒

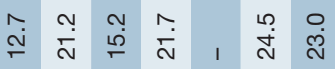
¿্்

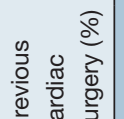

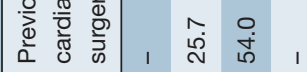

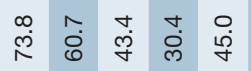
ஜூं , , 芦 $\stackrel{\oplus}{\leftarrow} \stackrel{+}{\leftarrow}$

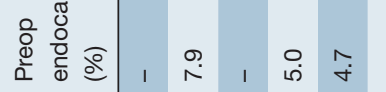

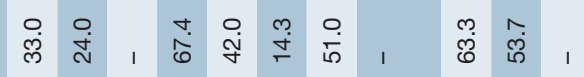
产造产

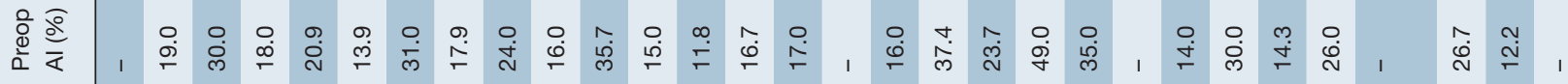

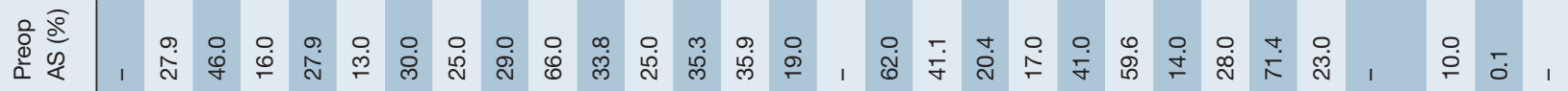

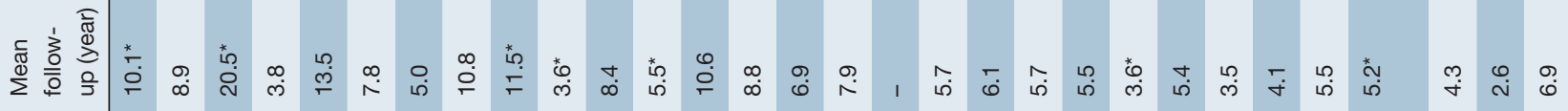

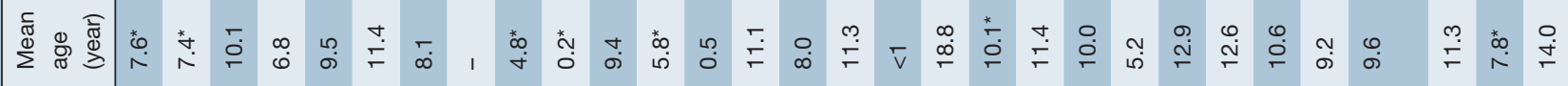

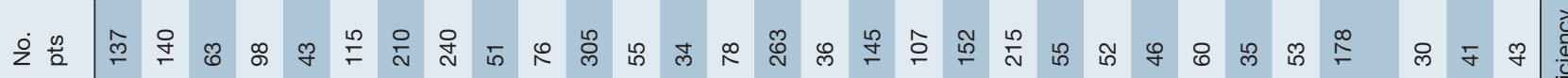

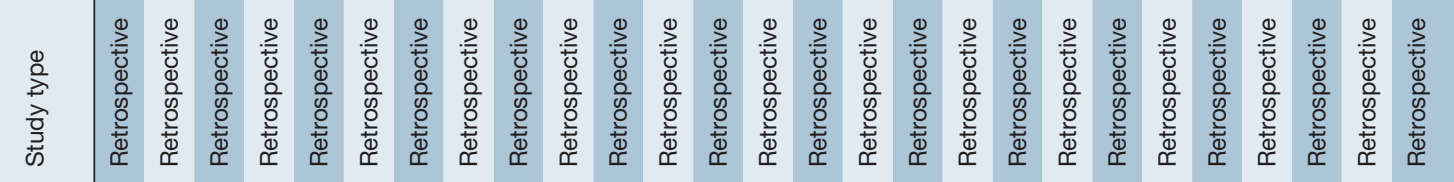

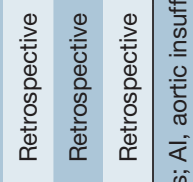

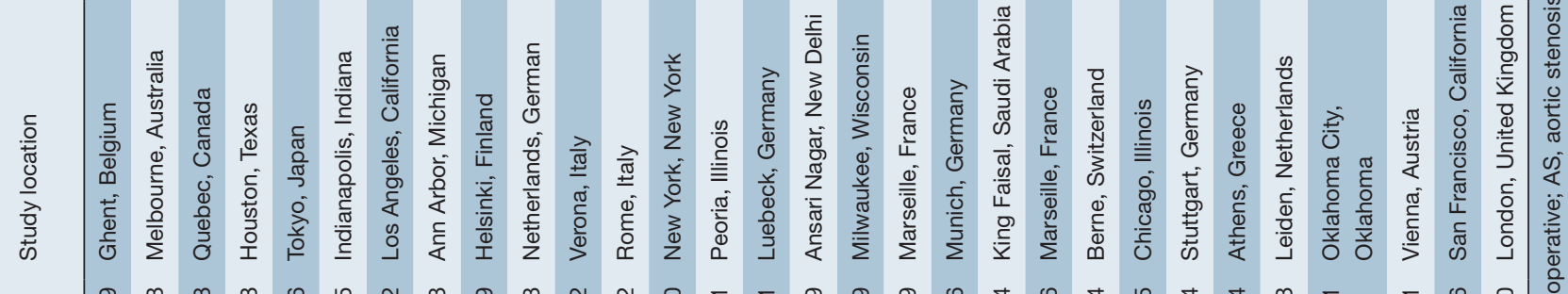

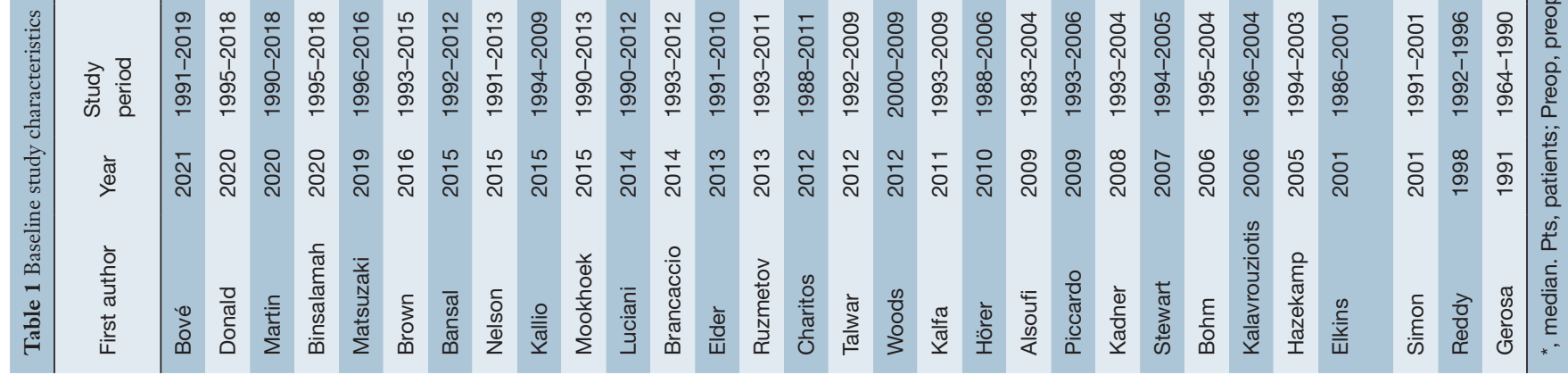


as pulmonary valve disease, Marfan disease, and immune disorders (i.e., lupus). A dilated or distorted aortic root was considered a relative contraindication due to higher risk of autograft dysfunction. However, a reinforced Ross procedure was still considered in some cases.

Patients undergoing the Ross procedure frequently underwent previous cardiac surgery (range, 25.7-80.5\%), and many patients required concomitant procedures (range, $12.7-56.1 \%$ ) or annular enlargement (up to $51.0 \%$ in some studies) at the time of operation.

\section{Study outcomes}

Table 2 details pooled outcome measures (mortality, reoperations, and complications) after the Ross procedure in the pediatric population. Early mortality rates ranged from 0.0 to $17.0 \%$, with studies focusing on neonatal and infant populations reporting higher mortality rates. Early mortality was reportedly between $11.8-17.0 \%$ in studies with a mean age less than 1 year of age. Late mortality rates were much lower, ranging from 0.04-1.83\%/year, and sudden unexpected unexplained death was rare (0.02-0.47 \%/year).

Reoperation can be required for either the pulmonary autograft and/or RVOT reconstruction. This review demonstrates that reoperation for the pulmonary autograft occurred at rates of $0.37-2.81 \%$ /year, and reoperation to address the RVOT was required at rates of 0.34-4.76 \%/year. Cause for pulmonary autograft reoperation was frequently due to neoaortic insufficiency with or without neoaortic dilation, and pulmonary homograft reintervention was most commonly due to pulmonary homograft obstruction or stenosis. Complications following the Ross procedure, including thromboembolic, bleeding, and endocarditisrelated events, occurred much less frequently (range, 0.00 0.58, 0.00-0.39, 0.00-1.68\%/year, respectively).

\section{Discussion}

The Ross operation has proven to be an excellent long-term operation for adults with aortic valve disease, and now it is used extensively in the neonatal and pediatric populations. Some of the great advantages of the Ross procedure include superior hemodynamic performance, growth potential, and no requirement for anticoagulant therapy. The is no age limit for the Ross procedure in the pediatric population, and the Ross procedure is being increasingly used in adolescent females of child-bearing age who anticipate pregnancy. Here, we continue to examine the advantages and disadvantages of the Ross operation in light of the acquired outcomes data surrounding the procedure in children.

\section{Mortality}

With the evolution of the Ross surgical technique and postoperative care over the past 50 years, mortality of pediatric patients undergoing this procedure has decreased. Multiple studies have shown that the Ross procedure can achieve durable, long-term results with an extremely low mortality rate. In this systematic review, early mortality was reported between $0.0-17.0 \%(34,42)$. This variability can be attributed to multiple factors: patient characteristics (i.e., younger age) as well as center experience.

Three studies specifically focusing on neonatal and infantile Ross outcomes had significantly higher perioperative mortality rates of $11.8 \%, 15.9 \%$, and $17.0 \%$ $(37,39,42)$. Most other studies reported early mortality rates between $1-5 \%$, with mortality rates being negligible in large series conducted at high-performing centers. It is important to recognize the difference in outcomes between neonatal and older pediatric populations. Given the increased neonatal mortality with the Ross procedure, it may be beneficial to consider delaying the Ross AVR in a neonate by utilizing other strategies such as balloon aortic valvuloplasty or aortic valve repair.

Compared to other AVR options, mortality rates in patients receiving the Ross procedure have been shown to be much lower than those undergoing non-Ross AVRs $(14,30)$. In a study by Brown et al., early mortality of the non-Ross AVR group was $9.5 \%$ compared to the $0.9 \%$ associated with the Ross cohort (30). Alsoufi et al. described 13 total operative deaths in their population: $5(2.3 \%)$ in the Ross group and $8(6.1 \%)$ in the mechanical AVR group (14). Risk factors for early mortality included mechanical valve, younger age at the time of replacement, and an underlying cause of aortic valve pathology other than rheumatic heart disease (14).

Upon our systematic review, late mortality was also reported to be favorable for the Ross procedure (0.04-1.83 $\% / y e a r)$, further demonstrating the procedure's durability once past the initial postoperative period. Long-term survival has also been shown to be superior with the Ross procedure compared to other types of AVR. Brown et al. noted a $94 \%$ survival rate for the Ross group, but only an $81 \%$ survival rate at 20 years for the non-Ross AVR group, making the Ross operation an attractive option for this young population (30). Similarly, Mazine et al. reported a significant difference in the long-term survival of patients 
Table 2 Primary and secondary study endpoints after the Ross procedure

\begin{tabular}{|c|c|c|c|c|c|c|c|c|c|}
\hline First author & Year & $\begin{array}{l}\text { Early } \\
\text { mortality (\%) }\end{array}$ & $\begin{array}{l}\text { Late } \\
\text { mortality } \\
\text { (\%/year) }\end{array}$ & $\begin{array}{l}\text { SUUD } \\
\text { (\%/year) }\end{array}$ & $\begin{array}{l}\text { Pulmonary } \\
\text { autograft } \\
\text { reoperation } \\
\text { (\%/year) }\end{array}$ & $\begin{array}{l}\text { RVOT } \\
\text { reoperation } \\
\text { (\%/year) }\end{array}$ & $\begin{array}{l}\text { TE/NT } \\
\text { (\%/year) }\end{array}$ & $\begin{array}{l}\text { Bleeding } \\
\text { (\%/year) }\end{array}$ & $\begin{array}{l}\text { Endocarditis } \\
\text { (\%/year) }\end{array}$ \\
\hline Bové & 2021 & 11.0 & 0.36 & - & 1.02 & 1.89 & - & - & - \\
\hline Donald & 2020 & 5.0 & 0.48 & 0.16 & 1.12 & 2.57 & - & - & - \\
\hline Matsuzaki & 2019 & 2.3 & 0.17 & - & 1.03 & 0.86 & - & - & 0.17 \\
\hline Brown & 2016 & 0.9 & 0.45 & 0.11 & 1.45 & 1.67 & 0.11 & - & 0.22 \\
\hline Bansal & 2015 & 4.3 & 0.05 & 0.05 & - & - & - & - & - \\
\hline Luciani & 2014 & 3.3 & 0.47 & 0.02 & 1.44 & 1.44 & 0.08 & 0.02 & 0.08 \\
\hline Brancaccio & 2014 & 13.0 & - & - & 1.98 & 3.97 & - & - & 0.33 \\
\hline Elder & 2013 & 11.8 & 0.14 & 0.14 & 0.28 & 4.16 & - & - & 0.28 \\
\hline Ruzmetov & 2013 & 3.9 & 0.58 & 0.29 & 2.91 & 2.33 & - & - & - \\
\hline Charitos & 2012 & 3.4 & 0.58 & 0.13 & 0.91 & 2.72 & 0.58 & 0.03 & 0.65 \\
\hline Talwar & 2012 & 2.8 & 1.40 & 0.18 & 1.75 & 0.70 & 0.18 & 0.18 & 0.70 \\
\hline Woods & 2012 & 15.9 & - & - & - & - & - & - & - \\
\hline Kalfa & 2011 & 0.0 & 0.49 & - & - & 0.82 & - & - & 0.16 \\
\hline Bohm & 2006 & 0.8 & 0.95 & 0.24 & 0.24 & 4.76 & 0.24 & 0.24 & 0.24 \\
\hline Kalavrouziotis & 2006 & 1.4 & 0.70 & 0.35 & 0.35 & 1.39 & - & - & - \\
\hline Hazekamp & 2005 & 5.7 & 1.03 & 0.17 & 1.72 & 1.03 & - & - & - \\
\hline Elkins & 2001 & 4.5 & 0.31 & - & 1.23 & 0.92 & 0.05 & - & 0.21 \\
\hline Simon & 2001 & 1.7 & 0.78 & 0.39 & 0.78 & 0.39 & 0.39 & 0.39 & 0.39 \\
\hline Reddy & 1998 & 2.4 & 0.47 & 0.47 & 1.89 & 0.47 & - & - & - \\
\hline Gerosa & 1991 & 11.6 & 1.68 & - & 1.68 & 0.34 & 0.00 & - & 1.68 \\
\hline
\end{tabular}

SUUD, sudden unexpected unexplained death; RVOT, right ventricular outflow tract; TE, thromboembolism; VT, valve thrombosis.

receiving the Ross procedure versus mechanical AVR at $5,10,15$, and 20 years postoperatively (43). A higher freedom from cardiac and valve related mortality was reported for the Ross AVR group at each interval (99.5\% vs. $97.4 \%$ at 5 years, $99.5 \%$ vs. $95.6 \%$ at 10 years, $97.3 \%$ vs. $93.4 \%$ at 15 years, $97.3 \%$ vs. $88.7 \%$ at 20 years) ( 43$)$.

Lastly, some studies have even reported long-term survival similar to the general population $(44,45)$. 


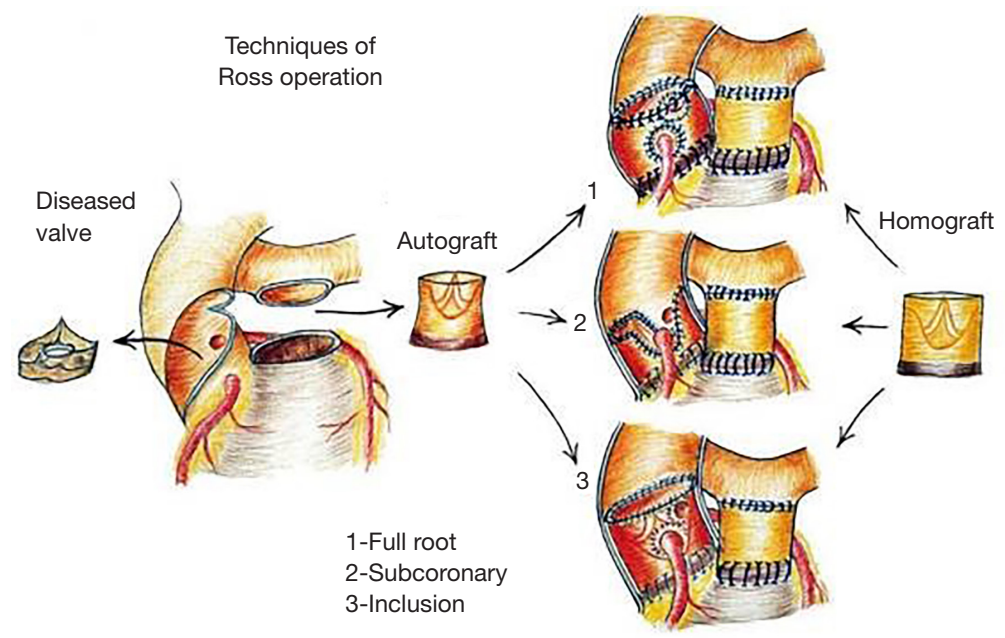

Figure 2 Ross operation techniques: full root [1], subcoronary [2], inclusion [3] (51).

Takkenberg et al. demonstrated excellent late survival with a 15 -year actuarial survival of $93.5 \%$ in children and a life expectancy $90-95 \%$ of the age- and sex-matched general population (44). In a study by Sievers et al. examining 1,779 young patients undergoing AVR, the Ross AVR resulted in a postoperative long-term survival comparable with that of the age- and gender-matched population (observed deaths: 101, expected deaths: 91; $\mathrm{P}=0.29$ ), further supporting the use of the Ross procedure for pediatric patients (45).

\section{Reoperation}

Despite excellent survival rates, reoperation can be required in patients undergoing the Ross procedure. Both the autograft and RVOT are susceptible to structural valve deterioration over time, and subsequently many patients that undergo the Ross procedure at less than 25 years of age are projected to undergo reintervention at some point during their lifetime, primarily due to structural valve deterioration (46). Our results reported that reoperation due to neoaortic valve failure occurs between $0.37-2.81 \% /$ year.

Following autograft root replacement, the main mechanism of autograft deterioration is progressive autograft regurgitation due to dilatation of the neoaortic root (10,47-49). Risk factors for pulmonary autograft dilatation have been shown to include age, preoperative aortic regurgitation, preoperative aortic annulus dilatation, and underlying cause of aortic pathology. Careful patient selection is critical to achieving optimal long-term outcomes following the Ross procedure.

Moreover, the acute increase in mechanical stress and strain on the autograft associated with transplanting the native pulmonary valve from the pulmonary to systemic circulation has been thought to contribute to autograft dilatation and insufficiency (50). With this in mind, strict postoperative systemic blood pressure control has been hypothesized to aid in reducing the risk of developing pulmonary autograft dilatation. However, the exact effectiveness of blood pressure control on pediatric Ross outcomes remains unknown.

Given the technical complexity of the Ross operation, variation in surgical technique as well as surgeon and center volume may also have an effect on long-term pulmonary autograft function. For example, the subcoronary implantation technique, the inclusion technique, and other types of reinforced Ross have all been shown to achieve mechanically more durable results with decreased risk of neoaortic dilatation and subsequent neoaortic insufficiency (Figure 2) $(17,41,51,52)$. However, these complex procedures are typically only performed by experienced surgeons at high-volume centers. Thus, the demanding nature of these techniques warrants surgeon and center familiarity with the procedure in order to ensure high quality results and provide the lowest odds for autograft reoperation.

Though reoperation is not negligible for those undergoing the Ross operation, rates of reoperation have been shown to be less when compared to other AVR procedures. In a study by Sharabiani et al., the difference in cumulative incidence of aortic valve reintervention between the Ross and mechanical AVR was $9.9 \%$ at 10 years, with the occurrence of reintervention being higher in the mechanical AVR group (53). This may be partially 
attributable growth potential, one of the reasons that the Ross procedure is greatly favored in the pediatric population.

While reintervention remains an undesirable complication, improvements in surgical techniques and postoperative management have led to great improvements in reoperative AVR, should it be required. Unfortunately, the advantages of the Ross procedure are lost with reoperation as the autograft is replaced with another prosthetic valve. However, in patients with autograft failure due to isolated neoaortic root dilatation with preserved neoaortic valve function, valvesparing root replacement strategies may allow for the longterm preservation of the benefits of the Ross procedure (54).

Since the operation involves two of the heart's native valves, the Ross procedure is classically known as the procedure with the potential to turn "one-valve disease" into "two-valve" disease (12). While not as dangerous, deterioration of the pulmonary homograft also poses a risk for reoperation in these patients. The studies included in this systematic review reported that reoperation due to RVOT stenosis or failure occurs between 0.34-4.76\%/year.

Contrary to the predominant regurgitation seen in pulmonary autograft failure, deterioration of the RVOT apparatus is typically characterized by stenosis. Risk factors for RVOT conduit degradation include: age, immunologic factors, as well as center and surgeon experience as previously described.

Age is an important factor related to RVOT conduit dysfunction, with younger age being more closely associated with higher rates of pulmonary homograft degeneration. This is especially true for the neonatal and infant population, which undergo even higher rates of RVOT reoperation (4.16-6.58\%/year) when compared to older children (0.34-4.76\%/year). While the exact mechanistic association underlying this relationship remains to be elucidated, agerelated differences in calcium metabolism, immune activity, somatic growth, and hemodynamics are thought to play a role (42,55-59). Upsizing the pulmonary homograft when possible may help to prevent late RVOT obstruction due to somatic growth and patient-prothesis mismatch.

Immunogenic factors have also been believed to play a role in RVOT allograft dysfunction. Host immune response as well as ABO blood group and human leukocyte antigen patient-donor mismatch have been shown to be associated with increased structural RVOT allograft degeneration $(60,61)$. With this in mind, allograft decellularization techniques that allow for preservation of the extracellular matrix while reducing the immune response and promoting autologous cell repopulation have shown positive results (42,55-59). However, longer follow-up and accumulation of larger patient series are required to provide more definitive evidence for this topic.

Despite the additional risk that the Ross procedure poses by potentially turning single-valve disease into double-valve disease, technological advancements regarding percutaneous interventions for the RVOT have shown promise for delaying open surgical reinterventions in qualifying pediatric Ross patients.

\section{Growth potential}

The Ross AVR is the only AVR strategy that allows for growth of the implanted valve, making it the procedure of choice in the growing child. The pulmonary autograft consists of the patient's autologous tissue and is not subject to immunogenic degenerative changes. Even though the Ross procedure involves removing the blood vessels supplying the arterial wall leading to possible deleterious effects on autograft vessel wall mechanics and growth, studies have continued to demonstrate growth of the pulmonary autograft and decreased likelihood of reoperation due to patient-prosthesis mismatch $(22,62)$.

Of note, some studies report varying patterns in growth following pulmonary autograft implantation. Solymar et al., along with many other previous reports, describes two patterns of autograft diameter increase: one rapid stage within the first year after surgery and a slower stage in the following years (62). Such a rapid increase in dimension is suggestive of passive dilation, which is unsurprising given that the number of elastic layers in the pulmonary artery is significantly less when compared to aortic tissue. Therefore, when exposed to higher systemic pressures, the pulmonary autograft undergoes an immediate period of quicker expansion. In spite of this, in clinical experience, excessive dilation to the extent of significant regurgitation is still exceedingly rare. Maintained function of the autograft may be due to patient growth and remodeling of the valve cusps (63).

Furthermore, the is no clear evidence of disproportionate progressive dilation after the first postoperative year. In a study by Simon et al., 30 children (mean age 11.3) were examined with serial echocardiographic follow-up for a mean follow-up of 4.3 years (22). During that time, the annulus diameter increased from 18 to $20 \mathrm{~mm}$, and the sinus diameter increased from 29 to $34 \mathrm{~mm}$. With this increase in autograft size, both the annulus and sinus paralleled the increase in body surface area with no evidence 
of disproportional dilatation. Hemodynamic measurements demonstrated physiologic peak gradients with no or trivial aortic insufficiency in this rapidly growing pediatric population of interest.

\section{Potential complications}

One of the most important advantages of the Ross procedure is its low thrombogenicity and avoidance of anticoagulation therapy. In this systematic review, thromboembolic events, and bleeding were reported after the Ross procedure at the respective rates of $0.00-0.58 \% /$ year and $0.02-0.39 \% / y e a r$. Endocarditis rates also tend to be quite low, with this review reporting an endocarditis rate of 0.00-1.68\%/year.

Comparatively, the Ross procedure fares much better in terms of these complications when compared to nonRoss AVR operations. Patients undergoing the Ross procedure do not require anticoagulation and therefore have a decreased risk of bleeding, allowing them to be able to participate in exercise activities without limitations (30). Despite not requiring anticoagulation, the incidence of thromboembolic events is lower in patients receiving the Ross procedure ( $0.9 \%$ vs. $2.4 \%$ ) given the natural state and hemodynamics of the valve (30). Further, the Ross AVR has been consistently shown to have a lower incidence of endocarditis $(1.7 \%$ vs. $10 \%)(16,30)$.

\section{Hemodynamics}

In addition to decreased complication rates, the Ross procedure is associated with a more favorable hemodynamic performance. The aortic valve and root are complex structures in terms of architecture and functionality. Utilization of an autologous native valve allows for more optimal hemodynamic and mechanical performance. Multiple studies have demonstrated that the pulmonary autograft is able to provide excellent support in the aortic position with valve competence and transaortic gradients similar to controls at baseline and with exercise, whereas moderately high gradients have been found in patients who received other valves, such as a homograft, in the aortic position $(64,65)$.

\section{Ross-Konno procedure}

Complex left ventricular outflow tract obstruction (LVOTO) involves a combination of a dysplastic aortic valve, hypoplastic annulus, and "tunnel-like" fibromuscular stenosis of the subvalvular region. While initial therapy for these patients may focus on the valvular level of obstruction using balloon valvuloplasty, open valvotomy, aortic valve repair, and/or subvalvular muscle resection, many of these patients experience recurrent obstruction or secondary acquired aortic regurgitation. Thus, combined AVR with resection or patch enlargement of the annular and subaortic region provides a definitive approach for patients in this group.

As the Ross procedure has gained interest in the pediatric population, the Ross-Konno procedure has similarly become excellent option for growing pediatric patients with multilevel LVOTO. The Ross AVR allows for a durable valve replacement with somatic growth, low risk of reoperation, and decreased need for anticoagulation. With a concurrent Konno procedure, patients gain a larger initial outflow tract and annulus diameter, which is especially favorable in the pediatric population. On the other hand, a disadvantage of the Ross-Konno procedure is the potential increase morbidity and mortality risk due to the nature of this patient population that tends to have more complex degrees of left-sided heart disease (including mitral valve abnormalities). However, when executed by surgeons who frequently perform this operation, clinical outcomes can be exceptional.

\section{Technical demands}

Given that many of the included studies examine data from single centers, it is possible to appreciate the variability in outcomes amongst different centers. While patient characteristics may also vary and contribute, it is critical to remember that the Ross AVR is a technically demanding operation that has a significant learning curve and potential for high associated morbidity. The subsequent risk of distortion of the neoaortic valve apparatus leading to early autograft failure always remains a concern, particularly amongst surgeons less familiar with this technique. Therefore, operator and center enterprise are essential for achieving satisfactory clinical outcomes.

\section{Limitations}

The authors recognize the following key limitations in regards to this systematic review. Firstly, the studies examined were all retrospective in nature. As such, the inherent limitations of combining data from retrospective studies should be taken into consideration. Further, most of 
the studies included in this review only reported data from a single center rather than drawing from large multicenter trials. Finally, the median follow-up of the included studies does not allow for the extension of observed outcomes beyond the first decade postoperatively.

\section{Conclusions}

The choice of aortic prosthesis in a pediatric patient is complex, with multiple factors often under consideration. The Ross procedure is a technically demanding operation that involves transplanting the patient's native pulmonary valve into the aortic position for pediatric patients with aortic valve disease. Reinterventions can be needed, mostly due to age-dependent structural valve degeneration of both the pulmonary autograft and allograft. However, if employed safely and strategically in the correct patients, the Ross operation represents the gold-standard option to replace the aortic valve in the pediatric population. The procedure offers a durable AVR option with low mortality, growth potential, better hemodynamics, and decreased risk of endocarditis without requiring anticoagulation.

In order to further validate the findings of this systematic review, it is crucial that pediatric Ross patients are followed into adulthood so that we may continue to learn and characterize the long-term outcomes related to this procedure. In addition, more studies comparing the Ross AVR to other AVR strategies in the pediatric population are warranted to improve insight into the long-term results related to AVR choice in these patients as they grow and age. The creation of a United States Ross Registry or North American Ross Registry would be pivotal in elucidating these outcomes, and we strongly propose the formation of a large collaborative database to further improve understanding of the Ross operation in the pediatric population.

\section{Acknowledgments}

Funding: None.

\section{Footnote}

Conflicts of Interest: The authors have no conflicts of interest to declare.

Open Access Statement: This is an Open Access article distributed in accordance with the Creative Commons Attribution-NonCommercial-NoDerivs 4.0 International License (CC BY-NC-ND 4.0), which permits the noncommercial replication and distribution of the article with the strict proviso that no changes or edits are made and the original work is properly cited (including links to both the formal publication through the relevant DOI and the license). See: https://creativecommons.org/licenses/by-nc-nd/4.0/.

\section{References}

1. Brown JW, Stevens LS, Holly S, et al. Surgical spectrum of aortic stenosis in children: a thirty-year experience with 257 children. Ann Thorac Surg 1988;45:393-403.

2. Salomon NW, Stinson EB, Oyer P, et al. Operative treatment of congenital aortic stenosis. Ann Thorac Surg 1978;26:452-60.

3. Hoffmann G, Lutter G, Cremer J. Durability of bioprosthetic cardiac valves. Dtsch Arztebl Int 2008;105:143-8.

4. Ross DN. Replacement of aortic and mitral valves with a pulmonary autograft. Lancet 1967;2:956-8.

5. Ross D, Jackson M, Davies J. The pulmonary autograft--a permanent aortic valve. Eur J Cardiothorac Surg 1992;6:113-6; discussion 117.

6. Luciani GB, Favaro A, Casali G, et al. Ross operation in the young: a ten-year experience. Ann Thorac Surg 2005;80:2271-7.

7. Clark JB, Pauliks LB, Rogerson A, et al. The Ross operation in children and young adults: a fifteen-year, single-institution experience. Ann Thorac Surg 2011;91:1936-41; discussion 1941-2.

8. Mazine A, El-Hamamsy I, Ouzounian M. The Ross procedure in adults: which patients, which disease? Curr Opin Cardiol 2017;32:663-71.

9. David TE, Omran A, Ivanov J, et al. Dilation of the pulmonary autograft after the Ross procedure. J Thorac Cardiovasc Surg 2000;119:210-20.

10. Kouchoukos NT, Masetti P, Nickerson NJ, et al. The Ross procedure: long-term clinical and echocardiographic follow-up. Ann Thorac Surg 2004;78:773-81; discussion 773-81.

11. Pasquali SK, Cohen MS, Shera D, et al. The relationship between neo-aortic root dilation, insufficiency, and reintervention following the Ross procedure in infants, children, and young adults. J Am Coll Cardiol 2007;49:1806-12. 
12. Laudito A, Brook MM, Suleman S, et al. The Ross procedure in children and young adults: a word of caution. J Thorac Cardiovasc Surg 2001;122:147-53.

13. Hörer J, Stierle U, Bogers AJ, et al. Re-interventions on the autograft and the homograft after the Ross operation in children. Eur J Cardiothorac Surg 2010;37:1008-14.

14. Alsoufi B, Al-Halees Z, Manlhiot C, et al. Mechanical valves versus the Ross procedure for aortic valve replacement in children: propensity-adjusted comparison of long-term outcomes. J Thorac Cardiovasc Surg 2009;137:362-370.e9.

15. Piccardo A, Ghez O, Gariboldi V, et al. Ross and Ross-Konno procedures in infants, children and adolescents: a 13-year experience. J Heart Valve Dis 2009;18:76-82; discussion 83.

16. Kadner A, Raisky O, Degandt A, et al. The Ross procedure in infants and young children. Ann Thorac Surg 2008;85:803-8.

17. Stewart RD, Backer CL, Hillman ND, et al. The Ross operation in children: effects of aortic annuloplasty. Ann Thorac Surg 2007;84:1326-30.

18. Kalavrouziotis G, Raja S, Ciotti G, et al. Medium-term results from pulmonary autografts after the Ross procedure in children and adolescents. Hellenic J Cardiol 2006;47:337-43.

19. Böhm JO, Botha CA, Horke A, et al. Is the Ross operation still an acceptable option in children and adolescents? Ann Thorac Surg 2006;82:940-7.

20. Hazekamp MG, Grotenhuis HB, Schoof PH, et al. Results of the Ross operation in a pediatric population. Eur J Cardiothorac Surg 2005;27:975-9.

21. Elkins RC, Lane MM, McCue C. Ross operation in children: late results. J Heart Valve Dis 2001; 10:736-41.

22. Simon P, Aschauer C, Moidl R, et al. Growth of the pulmonary autograft after the Ross operation in childhood. Eur J Cardiothorac Surg 2001;19:118-21.

23. Reddy VM, McElhinney DB, Phoon CK, et al. Geometric mismatch of pulmonary and aortic anuli in children undergoing the Ross procedure: implications for surgical management and autograft valve function. J Thorac Cardiovasc Surg 1998;115:1255-62; discussion 1262-3.

24. Gerosa G, McKay R, Davies J, et al. Comparison of the aortic homograft and the pulmonary autograft for aortic valve or root replacement in children. J Thorac Cardiovasc Surg 1991;102:51-60; discussion 60-1.
25. Bové T, Bradt N, Martens T, et al. The Pulmonary Autograft After the Ross Operation: Results of 25-Year Follow-Up in a Pediatric Cohort. Ann Thorac Surg 2021;111:159-67.

26. Donald JS, Wallace FRO, Naimo PS, et al. Ross Operation in Children: 23-Year Experience From a Single Institution. Ann Thorac Surg 2020;109:1251-9.

27. Martin E, Laurin C, Jacques F, et al. More Than 25 Years of Experience With the Ross Procedure in Children: A Single-Center Experience. Ann Thorac Surg 2020;110:638-44.

28. Binsalamah ZM, Ibarra C, Spigel Z, et al. Primary Aortic Root Replacement Outcomes and Risk Factors in Pediatric Patients. Ann Thorac Surg 2020;110:189-97.

29. Matsuzaki Y, Hiramatsu T, Agematsu K, et al. Longterm outcomes of Ross and Ross-Konno operations in patients under 15 years of age. Gen Thorac Cardiovasc Surg 2019;67:420-6.

30. Brown JW, Patel PM, Ivy Lin JH, et al. Ross Versus Non-Ross Aortic Valve Replacement in Children: A $22-$ Year Single Institution Comparison of Outcomes. Ann Thorac Surg 2016;101:1804-10.

31. Kallio M, Pihkala J, Sairanen H, et al. Long-term results of the Ross procedure in a population-based follow-up. Eur J Cardiothorac Surg 2015;47:e164-70.

32. Bansal N, Kumar SR, Baker CJ, et al. Age-Related Outcomes of the Ross Procedure Over 20 Years. Ann Thorac Surg 2015;99:2077-83; discussion 2084-5.

33. Nelson JS, Pasquali SK, Pratt CN, et al. Long-Term Survival and Reintervention After the Ross Procedure Across the Pediatric Age Spectrum. Ann Thorac Surg 2015;99:2086-94; discussion 2094-5.

34. Mookhoek A, Charitos EI, Hazekamp MG, et al. Ross Procedure in Neonates and Infants: A European Multicenter Experience. Ann Thorac Surg 2015;100:2278-84.

35. Luciani GB, Lucchese G, Carotti A, et al. Two decades of experience with the Ross operation in neonates, infants and children from the Italian Paediatric Ross Registry. Heart 2014;100:1954-9.

36. Brancaccio G, Polito A, Hoxha S, et al. The Ross procedure in patients aged less than 18 years: the midterm results. J Thorac Cardiovasc Surg 2014;147:383-8.

37. Elder RW, Quaegebeur JM, Bacha EA, et al. Outcomes of the infant Ross procedure for congenital aortic stenosis followed into adolescence. J Thorac Cardiovasc Surg 2013;145:1504-11. 
38. Ruzmetov M, Geiss DM, Shah JJ, et al. The Ross-Konno is a high-risk procedure when compared with the Ross operation in children. Ann Thorac Surg 2013;95:670-5.

39. Woods RK, Pasquali SK, Jacobs ML, et al. Aortic valve replacement in neonates and infants: an analysis of the Society of Thoracic Surgeons Congenital Heart Surgery Database. J Thorac Cardiovasc Surg 2012;144:1084-89.

40. Talwar S, Malankar D, Garg S, et al. Aortic valve replacement with biological substitutes in children. Asian Cardiovasc Thorac Ann 2012;20:518-24.

41. Charitos EI, Takkenberg JJ, Hanke T, et al. Reoperations on the pulmonary autograft and pulmonary homograft after the Ross procedure: An update on the German Dutch Ross Registry. J Thorac Cardiovasc Surg 2012;144:813-21; discussion 821-3.

42. Kalfa D, Feier H, Loundou A, et al. Cryopreserved homograft in the Ross procedure: outcomes and prognostic factors. J Heart Valve Dis 2011;20:571-81.

43. Mazine A, David TE, Rao V, et al. Long-Term Outcomes of the Ross Procedure Versus Mechanical Aortic Valve Replacement: Propensity-Matched Cohort Study. Circulation 2016;134:576-85.

44. Takkenberg JJ, Klieverik LM, Schoof PH, et al. The Ross procedure: a systematic review and meta-analysis. Circulation 2009;119:222-8.

45. Sievers HH, Stierle U, Charitos EI, et al. A multicentre evaluation of the autograft procedure for young patients undergoing aortic valve replacement: update on the German Ross Registry $\dagger$. Eur J Cardiothorac Surg 2016;49:212-8.

46. Etnel JRG, Grashuis P, Huygens SA, et al. The Ross Procedure: A Systematic Review, Meta-Analysis, and Microsimulation. Circ Cardiovasc Qual Outcomes 2018;11:e004748.

47. Simon-Kupilik N, Bialy J, Moidl R, et al. Dilatation of the autograft root after the Ross operation. Eur J Cardiothorac Surg 2002;21:470-3.

48. Elkins RC, Lane MM, McCue C, et al. Ross operation and aneurysm or dilation of the ascending aorta. Semin Thorac Cardiovasc Surg 1999;11:50-4.

49. Tantengco MV, Humes RA, Clapp SK, et al. Aortic root dilation after the Ross procedure. Am J Cardiol 1999;83:915-20.

50. Wisneski AD, Matthews PB, Azadani AN, et al. Human pulmonary autograft wall stress at systemic pressures prior to remodeling after the Ross procedure. J Heart
Valve Dis 2014;23:377-84.

51. Sievers HH. Ross procedure. HSR Proc Intensive Care Cardiovasc Anesth 2012;4:119-23.

52. Skillington PD, Mokhles MM, Takkenberg JJ, et al. Twenty-year analysis of autologous support of the pulmonary autograft in the Ross procedure. Ann Thorac Surg 2013;96:823-9.

53. Sharabiani MT, Dorobantu DM, Mahani AS, et al. Aortic Valve Replacement and the Ross Operation in Children and Young Adults. J Am Coll Cardiol 2016;67:2858-70.

54. Mookhoek A, de Kerchove L, El Khoury G, et al. European multicenter experience with valve-sparing reoperations after the Ross procedure. J Thorac Cardiovasc Surg 2015;150:1132-7.

55. Etnel JRG, Suss PH, Schnorr GM, et al. Fresh decellularized versus standard cryopreserved pulmonary allografts for right ventricular outflow tract reconstruction during the Ross procedure: a propensity-matched study. Eur J Cardiothorac Surg 2018;54:434-40.

56. da Costa FDA, Etnel JRG, Charitos EI, et al. Decellularized Versus Standard Pulmonary Allografts in the Ross Procedure: Propensity-Matched Analysis. Ann Thorac Surg 2018;105:1205-13.

57. da Costa FDA, Etnel JRG, Torres R, et al. Decellularized Allografts for Right Ventricular Outflow Tract Reconstruction in Children. World J Pediatr Congenit Heart Surg 2017;8:605-12.

58. Konertz W, Dohmen PM, Liu J, et al. Hemodynamic characteristics of the Matrix P decellularized xenograft for pulmonary valve replacement during the Ross operation. J Heart Valve Dis 2005;14:78-81.

59. Brown JW, Ruzmetov M, Eltayeb O, et al. Performance of SynerGraft decellularized pulmonary homograft in patients undergoing a Ross procedure. Ann Thorac Surg 2011;91:416-22; discussion 422-3.

60. Shaddy RE, Hunter DD, Osborn KA, et al. Prospective analysis of HLA immunogenicity of cryopreserved valved allografts used in pediatric heart surgery. Circulation 1996;94:1063-7.

61. Baskett RJ, Nanton MA, Warren AE, et al. Human leukocyte antigen-DR and ABO mismatch are associated with accelerated homograft valve failure in children: implications for therapeutic interventions. J Thorac Cardiovasc Surg 2003;126:232-9.

62. Solymar L, Südow G, Holmgren D. Increase in size of the pulmonary autograft after the Ross operation in 
children: growth or dilation? J Thorac Cardiovasc Surg 2000;119:4-9.

63. Yacoub M, El-Hamamsy I. The Ross operation in infants and children, when and how? Heart 2014;100:1905-6.

64. Phillips JR, Daniels CJ, Orsinelli DA, et al. Valvular hemodynamics and arrhythmias with exercise following the Ross procedure. Am J Cardiol 2001;87:577-83.

65. Pibarot P, Dumesnil JG, Briand M, et al. Hemodynamic performance during maximum exercise in adult patients with the ross operation and comparison with normal controls and patients with aortic bioprostheses. Am J Cardiol 2000;86:982-8.

Cite this article as: Moroi MK, Bacha EA, Kalfa DM. The Ross procedure in children: a systematic review. Ann Cardiothorac Surg 2021;10(4):420-432. doi: 10.21037/acs2020-rp-23 